\title{
Correction
}

\section{Correction: Antioxidant and Anti-Inflammatory Activities of Extracts from Cassia alata, Eleusine indica, Eremomastax speciosa, Carica papaya and Polyscias fulva Medicinal Plants Collected in Cameroon}

\section{The PLOS ONE Staff}

There is an error in the last sentence of the "Chemiluminescence Measurement of Plant Extracts Antioxidant Activity" section of the Materials and Methods. The correct sentence is: The data were reported as the percentage (\%) of inhibition (I) of the CL (chemiluminescence) signal and calculated as follows:

$$
\% I=100-(\text { CLsample } \times 100 \div \text { CLblank })
$$

where $\boldsymbol{C} \boldsymbol{L}$ sample is the chemiluminescence signal obtained for a sample in the presence of plant extracts and $\boldsymbol{C L}$ blank is the chemiluminescence signal obtained in the sample without plant extracts.

\section{Reference}

1. Sagnia B, Fedeli D, Casetti R, Montesano C, Falcioni G, et al. (2014) Antioxidant and Anti-Inflammatory Activities of Extracts from Cassia alata, Eleusine indica, Eremomastax speciosa, Carica papaya and Polyscias fulva Medicinal Plants Collected in Cameroon. PLoS ONE 9(8): e103999. doi:10.1371/journal.pone.0103999
Citation: The PLOS ONE Staff (2014) Correction: Antioxidant and AntiInflammatory Activities of Extracts from Cassia alata, Eleusine indica, Eremomastax speciosa, Carica papaya and Polyscias fulva Medicinal Plants Collected in Cameroon. PLoS ONE 9(10): e112573. doi:10.1371/journal.pone.0112573

Published October 30, 2014

Copyright: (C) 2014 The PLOS ONE Staff. This is an open-access article distributed under the terms of the Creative Commons Attribution License, which permits unrestricted use, distribution, and reproduction in any medium, provided the original author and source are credited. 